JAMA | US Preventive Services Task Force | RECOMMENDATION STATEMENT

IMPORTANCE An abdominal aortic aneurysm (AAA) is typically defined as aortic enlargement with a diameter of $3.0 \mathrm{~cm}$ or larger. The prevalence of AAA has declined over the past 2 decades among screened men 65 years or older in various European countries. The current prevalence of AAA in the United States is unclear because of the low uptake of screening. Most AAAs are asymptomatic until they rupture. Although the risk for rupture varies greatly by aneurysm size, the associated risk for death with rupture is as high as $81 \%$.

OBJECTIVE To update its 2014 recommendation, the USPSTF commissioned a review of the evidence on the effectiveness of 1-time and repeated screening for AAA, the associated harms of screening, and the benefits and harms of available treatments for small AAAs (3.0-5.4 cm in diameter) identified through screening.

POPULATION This recommendation applies to asymptomatic adults 50 years or older. However, the randomized trial evidence focuses almost entirely on men aged 65 to 75 years.

EVIDENCE ASSESSMENT Based on a review of the evidence, the USPSTF concludes with moderate certainty that screening for AAA in men aged 65 to 75 years who have ever smoked is of moderate net benefit. The USPSTF concludes with moderate certainty that screening for AAA in men aged 65 to 75 years who have never smoked is of small net benefit. The USPSTF concludes that the evidence is insufficient to determine the net benefit of screening for AAA in women aged 65 to 75 years who have ever smoked or have a family history of AAA. The USPSTF concludes with moderate certainty that the harms of screening for AAA in women aged 65 to 75 years who have never smoked and have no family history of AAA outweigh the benefits.

RECOMMENDATIONS The USPSTF recommends 1-time screening for AAA with ultrasonography in men aged 65 to 75 years who have ever smoked. (B recommendation) The USPSTF recommends that clinicians selectively offer screening for AAA with ultrasonography in men aged 65 to 75 years who have never smoked rather than routinely screening all men in this group. (C recommendation) The USPSTF recommends against routine screening for $A A A$ with ultrasonography in women who have never smoked and have no family history of AAA. (D recommendation) The USPSTF concludes that the current evidence is insufficient to assess the balance of benefits and harms of screening for AAA with ultrasonography in women aged 65 to 75 years who have ever smoked or have a family history of AAA. (I statement)
Editorial page 2177

Related article page 2219 and JAMA Patient Page page 2256

Audio and Supplemental content

CME Quiz at jamanetwork.com/learning and CME Questions page 2243

Related articles at jamanetworkopen.com jamasurgery.com 


\section{Summary of Recommendations}

\begin{tabular}{l|l|}
$\begin{array}{l}\text { The USPSTF recommends 1-time screening for abdominal aortic aneurysm } \\
\text { (AAA) with ultrasonography in men aged } 65 \text { to } 75 \text { years who have ever smoked. }\end{array}$ & B recommendation \\
\hline $\begin{array}{l}\text { The USPSTF recommends that clinicians selectively offer screening for AAA with } \\
\text { ultrasonography in men aged } 65 \text { to } 75 \text { years who have never smoked rather than } \\
\text { routinely screening all men in this group. Evidence indicates that the net benefit } \\
\text { of screening all men in this group is small. In determining whether this service } \\
\text { is appropriate in individual cases, patients and clinicians should consider the } \\
\text { balance of benefits and harms on the basis of evidence relevant to the patient's } \\
\text { medical history, family history, other risk factors, and personal values. }\end{array}$ & C recommetion \\
$\begin{array}{l}\text { The USPSTF recommends against routine screening for AAA with } \\
\text { ultrasonography in women who have never smoked and have no family } \\
\text { history of AAA. }\end{array}$ & D recommendation \\
\hline $\begin{array}{l}\text { The USPSTF concludes that the current evidence is insufficient to assess the } \\
\text { balance of benefits and harms of screening for AAA with ultrasonography in } \\
\text { women aged } 65 \text { to } 75 \text { years who have ever smoked or have a family history } \\
\text { of AAA. }\end{array}$ & I statement \\
\hline
\end{tabular}

See the Figure for a more detailed summary of the recommendation for clinicians. See the "Practice Considerations" section for more information on each of these populations. USPSTF indicates US Preventive Services Task Force.
Importance

An AAA is typically defined as aortic enlargement with a diameter of $3.0 \mathrm{~cm}$ or larger. The prevalence of AAA has declined over the past 2 decades among screened men 65 years or older in various countries such as the United Kingdom, New Zealand, Sweden, and Denmark. ${ }^{1-10}$ Population-based studies in men older than 60 years have found an AAA prevalence ranging from $1.2 \%$ to $3.3 \%{ }^{1-10}$ The reduction in prevalence is attributed to the decrease in smoking prevalence over time. Previous prevalence rates of AAA reported in population-based screening studies ranged from $1.6 \%$ to $7.2 \%$ of the general population 60 to 65 years or older. ${ }^{1}$ The current prevalence of AAA in the United States is unclear because of the low uptake of screening. ${ }^{1}$ Most AAAs are asymptomatic until they rupture. Although the risk for rupture varies greatly by aneurysm size, the associated risk for death with rupture is as high as $81 \%$. ${ }^{1,11}$

\section{USPSTF Assessment of Magnitude of Net Benefit}

The USPSTF concludes with moderate certainty that screening for AAA in men aged 65 to 75 years who have ever smoked is of moderate net benefit (Figure and Table; see the eFigure in the Supplement for explanation of USPSTF grades and levels of evidence).

The USPSTF concludes with moderate certainty that screening for AAA in men aged 65 to 75 years who have never smoked is of small net benefit (Figure and Table).

The USPSTF concludes that the evidence is insufficient to determine the net benefit of screening for AAA in women aged 65 to 75 years who have ever smoked or have a family history of AAA (Figure and Table).

The USPSTF concludes with moderate certainty that the harms of screening for AAA in women aged 65 to 75 years who have never smoked and have no family history of AAA outweigh the benefits (Figure and Table).
For more details on the methods the USPSTF uses to determine the net benefit, see the USPSTF Procedure Manual. ${ }^{12}$

\section{Practice Considerations}

Patient Population Under Consideration

Based on the scope of the evidence review, this recommendation applies to asymptomatic adults 50 years or older. However, the randomized trial evidence focuses almost entirely on men aged 65 to 75 years. In this Recommendation Statement, the recommendations are stratified by "men" and "women," although the net benefit estimates are driven by biologic sex (ie, male/female) rather than gender identity. Persons should consider their sex at birth to determine which recommendation best applies to them.

\section{Assessment of Risk}

Important risk factors for AAA include older age, male sex, smoking, and having a first-degree relative with an AAA. ${ }^{13-16}$ Other risk factors include a history of other vascular aneurysms, coronary artery disease, cerebrovascular disease, atherosclerosis, hypercholesterolemia, and hypertension. ${ }^{17-19}$ Factors associated with a reduced risk include African American race, Hispanic ethnicity, Asian ethnicity, and diabetes. ${ }^{13,20-24}$ Risk factors for AAA rupture include older age, female sex, smoking, and elevated blood pressure. ${ }^{1}$ Clinicians should consider the presence of comorbid conditions and not offering screening if patients are unable to undergo surgical intervention or have a reduced life expectancy.

\section{Smoking Status}

Epidemiologic literature commonly defines an "ever smoker" as someone who has smoked 100 or more cigarettes. Indirect evidence shows that smoking is the strongest predictor of AAA prevalence, growth, and rupture rates. ${ }^{1}$ There is a dose-response relationship, as greater smoking exposure is associated with an increased risk for AAA. ${ }^{1}$ 


\begin{tabular}{|c|c|}
\hline \multicolumn{2}{|l|}{ December 2019} \\
\hline \multirow{4}{*}{$\begin{array}{l}\text { What does the USPSTF } \\
\text { recommend? }\end{array}$} & $\begin{array}{l}\text { For men aged } 65 \text { to } 75 \text { years who have ever smoked: Grade B } \\
\text { Perform 1-time screening for abdominal aortic aneurysm (AAA) with ultrasonography in men who have a history of smoking }\end{array}$ \\
\hline & $\begin{array}{l}\text { For men aged } 65 \text { to } 75 \text { years who have never smoked: Grade C } \\
\text { Selectively offer screening to men who do not have a history of smoking, rather than routinely screening all men in this group. }\end{array}$ \\
\hline & $\begin{array}{l}\text { For women who have never smoked and have no family history of AAA: Grade D } \\
\text { Do not screen women who have never smoked and do not have a family history of AAA. }\end{array}$ \\
\hline & $\begin{array}{l}\text { For women aged } 65 \text { to } 75 \text { years who have ever smoked or have a family history of AAA: I statement } \\
\text { Evidence is insufficient to assess the balance of benefits and harms of screening for AAA with ultrasonography in women } \\
\text { aged } 65 \text { to } 75 \text { years who have ever smoked or have a family history of AAA. }\end{array}$ \\
\hline $\begin{array}{l}\text { To whom does this } \\
\text { recommendation apply? }\end{array}$ & Asymptomatic adults \\
\hline What's new? & $\begin{array}{l}\text { This recommendation is consistent with the } 2014 \text { USPSTF recommendation. Family history (first-degree relative) of AAA has } \\
\text { been added as a risk factor for screening decisions in women. }\end{array}$ \\
\hline $\begin{array}{l}\text { How to implement this } \\
\text { recommendation? }\end{array}$ & $\begin{array}{l}\text { 1. Assess risk. Risk factors for AAA include older age, male sex, smoking, and having a first-degree relative with an AAA. } \\
\text { The recommendation varies based on a patient's sex, age, and smoking history. "Ever smoker" is commonly defined as } \\
\text { smoking } 100 \text { or more cigarettes. } \\
\text { 2. Screen. Abdominal duplex ultrasonography is the standard approach for AAA screening. } \\
\text { a. Screen men aged } 65 \text { to } 75 \text { years who have ever smoked. } \\
\text { b. Selectively offer screening to men aged } 65 \text { to } 75 \text { years who have never smoked. Evidence shows that the overall benefit } \\
\text { for screening all men in this group is small. To determine whether this service is appropriate, patients and clinicians } \\
\text { should consider the patient's medical history, family history, other risk factors, and personal values. } \\
\text { For those who screen positive, treatment of AAA will depend on aneurysm size, the risk of rupture, and the risk } \\
\text { of operative mortality. }\end{array}$ \\
\hline How often? & One-time screening \\
\hline $\begin{array}{l}\text { What are other } \\
\text { relevant USPSTF } \\
\text { recommendations? }\end{array}$ & $\begin{array}{l}\text { The USPSTF has made recommendations on screening for carotid artery stenosis and screening for peripheral arterial disease. } \\
\text { These recommendations are available at https://www.uspreventiveservicestaskforce.org. }\end{array}$ \\
\hline
\end{tabular}

The USPSTF recognizes that clinical decisions involve more considerations than evidence alone. Clinicians should understand the evidence but individualize decision-making to the specific patient or situation.

AAA indicates abdominal aortic aneurysm; USPSTF, US Preventive Services Task Force.

\section{Family History}

Family history of AAA in a first-degree relative doubles the risk of developing AAA. ${ }^{25}$ The risk of developing an AAA is stronger with a female first-degree relative (odds ratio [OR], 4.32) than with a male first-degree relative $(\mathrm{OR}, 1.61) .{ }^{1,25}$ However, evidence is lacking on whether persons with family history experience a different natural history or surgical outcomes than those without such a history. ${ }^{1}$

\section{Screening Tests}

The primary method of screening for AAA is conventional abdominal duplex ultrasonography. ${ }^{26}$ Screening with ultrasonography is noninvasive, is simple to perform, has high sensitivity (94\%-100\%) and specificity (98\%-100\%) for detecting AAA, ${ }^{1,27-31}$ and does not expose patients to radiation. Computed tomography is an accurate tool for identifying AAA; however, it is not recommended as a screening method because of the potential for harms from radiation exposure. ${ }^{1}$ Physical examination has been used in practice but has low sensitivity (39\%-68\%) and specificity (75\%) and is not recommended for screening. ${ }^{32}$

\section{Screening Intervals}

Evidence is adequate to support 1-time screening for men who have ever smoked. All of the population-based randomized clinical trials
(RCTs) of AAA screening used a 1-time screening approach; 7 fairto good-quality cohort studies and 1 fair-quality case-control study ( $n=6785$ ) show that AAA-associated mortality over 5 to 12 years is rare $(<3 \%)$ in men with initially normal results on ultrasonography (defined as an AAA $<3 \mathrm{~cm}$ in diameter). ${ }^{1}$

\section{Treatment}

Treatment of AAA depends on aneurysm size, the risk of rupture, and the risk of operative mortality. Larger size is associated with an increased risk of rupture. The annual risk for rupture is nearly $0 \%$ for persons with AAAs between 3.0 and $3.9 \mathrm{~cm}$ in diameter, $1 \%$ for those with AAAs between 4.0 and $4.9 \mathrm{~cm}$ in diameter, and $11 \%$ for those with AAAs between 5.0 and $5.9 \mathrm{~cm}$ in diameter. ${ }^{1}$ Surgical repair is standard practice for men with an AAA of $5.5 \mathrm{~cm}$ or larger in diameter or an AAA larger than $4.0 \mathrm{~cm}$ in diameter that has rapidly increased in size (defined as an increase of $1.0 \mathrm{~cm}$ in diameter over a 1-year period). Endovascular aneurysm repair (EVAR) has become the most common approach for elective AAA repair. Open repair is a time-tested, effective treatment for AAA. In the United States, $80 \%$ of intact AAA repairs and $52 \%$ of ruptured AAA repairs are performed using EVAR. ${ }^{1}$

The majority of screen-detected AAAs ( $\geq 90 \%$ ) are between 3.0 and $5.5 \mathrm{~cm}$ in diameter and thus below the usual threshold for 


\begin{tabular}{|c|c|c|c|c|}
\hline \multirow[b]{2}{*}{ Rationale } & \multicolumn{2}{|l|}{ Men } & \multicolumn{2}{|l|}{ Women } \\
\hline & Ever Smoked & Never Smoked & Ever Smoked or Family History & $\begin{array}{l}\text { Never Smoked and No Family } \\
\text { History }\end{array}$ \\
\hline Detection & $\begin{array}{l}\text { There is adequate evidence } \\
\text { that ultrasonography is a safe } \\
\text { and accurate screening test } \\
\text { for AAA }\end{array}$ & $\begin{array}{l}\text { There is adequate evidence } \\
\text { that ultrasonography is a safe } \\
\text { and accurate screening test } \\
\text { for AAA }\end{array}$ & $\begin{array}{l}\text { There is adequate evidence } \\
\text { that ultrasonography is a safe } \\
\text { and accurate screening test } \\
\text { for AAA }\end{array}$ & $\begin{array}{l}\text { There is adequate evidence } \\
\text { that ultrasonography is a safe } \\
\text { and accurate screening test } \\
\text { for AAA }\end{array}$ \\
\hline $\begin{array}{l}\text { Benefits of early detection and } \\
\text { treatment (based on direct or } \\
\text { indirect evidence) }\end{array}$ & $\begin{array}{l}\text { There is adequate evidence } \\
\text { that } 1 \text {-time screening for AAA } \\
\text { with ultrasonography results } \\
\text { in a moderate benefit in men } \\
\text { aged } 65 \text { to } 75 \text { y who have ever } \\
\text { smoked }\end{array}$ & $\begin{array}{l}\text { There is adequate evidence } \\
\text { that } 1 \text {-time screening for AAA } \\
\text { with ultrasonography results } \\
\text { in a small benefit in men aged } \\
65 \text { to } 75 \text { y who have never } \\
\text { smoked }\end{array}$ & $\begin{array}{l}\text { There is inadequate evidence } \\
\text { to conclude whether } 1 \text {-time } \\
\text { screening for AAA with } \\
\text { ultrasonography is beneficial } \\
\text { in women aged } 65 \text { to } 75 \mathrm{y} \text { who } \\
\text { have ever smoked or have a } \\
\text { family history of AAA }\end{array}$ & $\begin{array}{l}\text { There is adequate evidence } \\
\text { that } 1 \text {-time screening for AAA } \\
\text { with ultrasonography results } \\
\text { in no benefit in women who } \\
\text { have never smoked and have } \\
\text { no family history of AAA }\end{array}$ \\
\hline $\begin{array}{l}\text { Harms of early detection and } \\
\text { treatment }\end{array}$ & $\begin{array}{l}\text { There is adequate evidence } \\
\text { that the harms associated with } \\
\text { 1-time screening for AAA with } \\
\text { ultrasonography are small to } \\
\text { moderate }\end{array}$ & $\begin{array}{l}\text { There is adequate evidence } \\
\text { that the harms associated with } \\
\text { 1-time screening for AAA with } \\
\text { ultrasonography are small to } \\
\text { moderate }\end{array}$ & $\begin{array}{l}\text { There is adequate evidence } \\
\text { that the harms associated with } \\
\text { 1-time screening for AAA with } \\
\text { ultrasonography are small to } \\
\text { moderate }\end{array}$ & $\begin{array}{l}\text { There is adequate evidence } \\
\text { that the harms associated with } \\
\text { 1-time screening for AAA with } \\
\text { ultrasonography are small to } \\
\text { moderate }\end{array}$ \\
\hline USPSTF assessment & $\begin{array}{l}\text { There is moderate certainty } \\
\text { that screening for AAA with } \\
\text { ultrasonography in men aged } \\
65 \text { to } 75 \text { y who have ever } \\
\text { smoked has a moderate net } \\
\text { benefit }\end{array}$ & $\begin{array}{l}\text { There is moderate certainty } \\
\text { that screening for AAA with } \\
\text { ultrasonography in men aged } \\
65 \text { to } 75 \text { y who have never } \\
\text { smoked has a small net } \\
\text { benefit }\end{array}$ & $\begin{array}{l}\text { The benefits and harms of } \\
\text { screening for AAA with } \\
\text { ultrasonography in women } \\
\text { aged } 65 \text { to } 75 \text { y who have ever } \\
\text { smoked or have a family } \\
\text { history of AAA are uncertain, } \\
\text { and the balance of benefits } \\
\text { and harms cannot be } \\
\text { determined }\end{array}$ & $\begin{array}{l}\text { There is moderate certainty } \\
\text { that the harms of screening } \\
\text { for AAA with ultrasonography } \\
\text { in women who have never } \\
\text { smoked and have no family } \\
\text { history of AAA outweigh the } \\
\text { benefits }\end{array}$ \\
\hline $\begin{array}{l}\text { Abbreviations: AAA, abdominal } \\
\text { Services Task Force. }\end{array}$ & ic aneurysm; USPSTF, US P & $\begin{array}{l}\text { a See the eFig } \\
\text { levels of evi }\end{array}$ & $\begin{array}{l}\text { ure in the Supplement for explan } \\
\text { ence. }\end{array}$ & ion of USPSTF grades and \\
\hline
\end{tabular}

surgery. The current standard of care for patients with stable smaller aneurysms is to maintain ultrasound surveillance at regular intervals because the risk of rupture is small. Recommended surveillance intervals for monitoring the growth of small AAAs vary across guideline groups, and adherence with surveillance guidelines has been reported to be as low as $65 \%$. ${ }^{1}$ Repairing smaller aneurysms with a lower risk of rupture increases the harms and reduces the benefits of screening.

Suggestions for Practice Regarding the I Statement Potential Preventable Burden

The estimated prevalence of AAA in women is reportedly less than that in men. ${ }^{1}$ The Chichester trial reported a prevalence in women that was one-sixth of the prevalence in men (1.3\% vs $7.6 \%)$, and most AAA-related deaths occurred in women 80 years or older (70\% vs $<50 \%$ in men). ${ }^{33}$ In women, small AAAs have an increased risk of rupture, and rupture at an older age than in men. ${ }^{1}$ Studies estimate that one-fourth to one-third of women have an AAA with a diameter below the current $5.5-\mathrm{cm}$ threshold at the time of rupture. ${ }^{1}$

\section{Potential Harms}

Operative mortality associated with AAA is higher in women than in men. Women had higher 30-day mortality rates (2.31\%) than men (1.37\%) after EVAR procedures (OR, 1.67 [95\% Cl, 1.38-2.04]) and open repair (5.37\% vs $2.82 \%$; OR, 1.76 [95\% Cl, 1.35-2.30]). ${ }^{1,34}$ Women also experience higher rates of other harms, such as major surgical complications and hospital readmission, after elective open repair or EVAR compared with men. ${ }^{1}$

\section{Current Practice}

Evidence is insufficient to accurately characterize current practice patterns related to screening for AAA in women.
The standard of care for elective repair is that patients with an AAA of $5.5 \mathrm{~cm}$ or larger in diameter should be referred for surgical intervention with either open repair or EVAR. ${ }^{1}$ This recommendation is based on RCTs conducted in men. The AAA size needed for surgical intervention in women may differ. As a result, guidelines from the Society for Vascular Surgery recommend repairing AAAs between 5.0 and $5.4 \mathrm{~cm}$ in diameter in women. ${ }^{26}$ However, concerns about poorer surgical outcomes in women, who have more complex anatomy and smaller blood vessels, have led some to caution against lowering the threshold for surgical intervention in women. ${ }^{1}$

\section{Update of Previous USPSTF Recommendation}

This recommendation incorporates new evidence and replaces the 2014 USPSTF recommendation. ${ }^{35}$ It is consistent with the 2014 USPSTF recommendation, which was a B recommendation for 1-time screening for AAA with ultrasonography in asymptomatic men aged 65 to 75 years who have ever smoked, a $C$ recommendation for selective screening in men aged 65 to 75 years who have never smoked, a $D$ recommendation against routine screening in asymptomatic women who have never smoked, and an I statement for women aged 65 to 75 years who have ever smoked.

\section{Supporting Evidence}

\section{Scope of Review}

The USPSTF commissioned a systematic evidence review to update its 2014 recommendation on screening for AAA. The USPSTF examined evidence regarding the effectiveness of 1-time and repeated screening for AAA, the associated harms of screening, and 
the benefits and harms of available treatments for small AAAs (3.0-5.4 cm in diameter) identified through screening.

Accuracy of Screening Tests and Risk Assessment Ultrasonography is the primary method used to screen for AAA in primary care because of its high sensitivity (94\%-100\%) and specificity (98\%-100\%). ${ }^{1}$ It is also noninvasive, is simple to perform, and does not expose patients to radiation.

\section{Benefits of Early Detection and Treatment Screening}

Four large, population-based RCTs $(n=134271)$ that predominantly enrolled men 65 years or older examined the effectiveness of 1-time screening for AAA: the good-quality Multicenter Aneurysm Screening Study (MASS) $(n=67800)^{36}$; the good-quality Viborg County, Denmark, screening trial $(n=12639)^{13}$; the fairquality Chichester, United Kingdom, screening trial $(n=15382)^{37}$; and the fair-quality Western Australia screening trial $(n=38480){ }^{38}$ Reported mean (or median) ages ranged from 67.7 to 72.6 years; the oldest participants were aged 83 years. ${ }^{1}$ The Western Australia screening trial $^{38}$ reported outcomes by smoking status in the screened group. The trial was underpowered to detect differences in subpopulations. No comparisons in the unscreened group were reported. ${ }^{1,39}$ None of the 4 population-based screening RCTs reported family history of AAA in the trial populations. ${ }^{1}$

The prevalence of AAA in male screening participants ranged from $4.0 \%$ to $7.6 \%$ across the studies. Most screen-detected AAAs were small ( $\leq 4$ to $4.5 \mathrm{~cm}$ in diameter); $0.3 \%$ to $0.6 \%$ of screened participants had an AAA measuring $5 \mathrm{~cm}$ or larger or $5.5 \mathrm{~cm}$ or larger in diameter. ${ }^{1}$ Two of the population-based screening trials analyzed AAA-associated mortality by age. The Viborg trial found similar risk reduction in AAA-related mortality in screening men aged 64 to 65 years compared with men aged 66 to 73 years. ${ }^{13}$ The Western Australia trial found no AAA-associated mortality benefit in men aged 65 to 74 years (rate ratio, 0.92 [95\% Cl, 0.62-1.36]) at 12.8year follow-up; results were similar to findings for men aged 64 to 83 years. ${ }^{1,38}$

As noted previously, only the Chichester trial included women (aged 65-80 years). It found a low prevalence of AAA in women (1.3\%), and $75 \%$ of screen-detected AAAs in women were 3.0 to $3.9 \mathrm{~cm}$ in diameter. Rupture rates ( $0.2 \%$ in both groups), AAAspecific mortality (0.06\% vs $0.04 \%$ in both groups), and all-cause mortality (10.7\% vs $10.2 \%)$ at 5 years did not statistically significantly differ between the invitation-to-screening and control groups. ${ }^{1,33}$ The trial was underpowered to draw definitive conclusions about health outcomes in women. Although the risk for rupture at a smaller aneurysm diameter seems to be higher in women than in men, ${ }^{1,40}$ the overall rupture rate in women is low. In the Chichester trial, more than two-thirds of deaths from AAA occurred in women 80 years or older. ${ }^{1,33}$

Pooled analysis of AAA-related mortality from the 4 trials showed a statistically significant $35 \%$ reduction associated with invitation to screening (Peto OR, 0.65 [95\% Cl, 0.57-0.74]; $\left.r^{2}=80 \%\right) .{ }^{1}$ The number needed to screen was 305 men $(95 \% \mathrm{Cl}$, 248-411) to prevent 1 AAA death. The MASS and Viborg trials each found a statistically significant reduction in AAA-related mortality in the groups invited to screening compared with the control groups up to 13 years after screening (hazard ratio [HR],
0.58 [95\% Cl, 0.49-0.69] and 0.34 [95\% Cl, 0.20-0.57], respectively). ${ }^{13,36}$ The Chichester trial reported an HR of less than 1 (HR, 0.89 [95\% Cl, 0.60-1.32]), but it was not statistically significant. ${ }^{1,37}$ Pooled analysis of all available trials also showed no effect on all-cause mortality (relative risk, 0.99 [95\% Cl, 0.981.00]; $l^{2}=0 \%$ ). ${ }^{1}$ Of the individual trials, only MASS showed a statistically significant benefit of screening for all-cause mortality at up to 15-year follow-up (HR, 0.97 [95\% Cl, 0.95-0.99]). Invitation to screening was associated with a statistically significant reduced rate of rupture in the pooled analysis of the 4 trials (Peto OR, 0.62 [95\% Cl, 0.55-0.70]; $\left.I^{2}=53 \%\right) .{ }^{1}$ The number needed to screen was 246 men $(95 \%$ Cl, 207-311) to prevent 1 AAA rupture. Pooled results of the trials showed a reduction in emergency surgery in the invited-to-screening group (Peto OR, $0.57[95 \% \mathrm{Cl}, 0.48$ 0.68 ]; $\left.l^{2}=27 \%\right)$. ${ }^{1}$ Screening 1000 men for AAA would decrease the number of emergency operations by 2 ( $95 \% \mathrm{Cl}, 2-2){ }^{1}$

\section{Treatment}

Four trials evaluated early surgical intervention compared with surveillance of smaller aneurysms (4-5.4 cm in diameter). ${ }^{41-44}$ Two good-quality open repair trials $(n=2226)$ and 2 fair-quality EVAR trials $(n=1088)$ showed no differences in all-cause and AAA-related mortality. However, there was a reduction in rupture rate with early open surgery compared with surveillance for small $\mathrm{AAAs}^{12,16,37,38}$ in the Aneurysm Detection and Management (ADAM) Veterans Affairs trial (relative risk, 0.18 [95\% Cl, 0.04$0.81]$ ) and the UK Small Aneurysm Trial (UKSAT) (relative risk, 0.51 [95\% Cl, 0.26-0.99]). 1,41,42 Individual patient data metaanalysis of the 2 early open vs surveillance trials (ADAM and UKSAT) reported no differences in all-cause mortality effect by sex or age. ${ }^{1,36,37}$ The UKSAT trial reported no difference in allcause mortality by smoking status; there were no analyses stratifying by family history or race/ethnicity. ${ }^{1}$

Seven pharmacotherapy RCTs ( $n=1553$ ) of antibiotics, antihypertensive medications (eg, angiotensin-converting enzyme inhibitors, calcium channel blockers, and propranolol), and a mast cell stabilizer showed no significant effect on AAA growth compared with placebo. ${ }^{1}$

\section{Harms of Screening and Treatment}

An individual's risk for death related to elective surgery for AAA is lower than that related to emergency surgery for aneurysm rupture. However, the increase in the overall rates of detection and surgery in the screening groups still potentially represents a harm. The extent of overdiagnosis and overtreatment is difficult to estimate.

Each of the 4 older screening trials and a more recent population-based screening RCT $(n=18614)$, the Viborg Vascular (VIVA) trial, showed an increase in elective operations in the intervention vs control group. ${ }^{1,45}$ There were approximately $40 \%$ more operations in the invitation-to-screen group than in the control group (5 studies; $n=175$ 085; Peto OR, 1.44 [95\% Cl, 1.34-1.55]), driven primarily by an increase in elective operations ( 5 studies; $\mathrm{n}=175$ 085; Peto OR, 1.75 [95\% Cl, 1.61-1.90]). ${ }^{1}$ There was no statistically significant difference in 30-day mortality rates between the invited and control groups for either elective or emergency operations at 12- to 15-year follow-up. ${ }^{1}$

Five studies ( $n=2734)$ reported mixed results on quality-oflife outcomes. ${ }^{1}$ Overall, there were no substantial differences on 
quality-of-life measures or anxiety or depression scores at up to 12 months of follow-up between patients who screened positive for an AAA and patients who screened negative or were unscreened. ${ }^{1}$

Two trials of early open repair vs surveillance (ADAM and UKSAT trials) reported a $50 \%$ higher rate of procedures in the early intervention group, with no difference in 30-day operative mortality. ${ }^{1,41,42}$ Readmission rates at 30 days were similar, and major surgical complications were lower in the early intervention group. Analysis of quality-of-life measures showed mixed results; although there was generally a decline in both groups over time, there were no statistically significant differences between the groups for up to 1 to 2 years. Only the ADAM trial showed higher general health scores in the early repair group in the first 2 years, but this difference did not persist over time. ${ }^{1}$ One trial reported an increased incidence of impotence in the early repair group at up to 4 years' follow-up. ${ }^{1}$

Registry harms data were generally comparable to the findings of the 2 trials, with the exception of reintervention rates, which were higher in the registries than in the ADAM trial. ${ }^{1}$

Two trials of early EVAR vs surveillance reported approximately $100 \%$ more procedures in the early intervention group and similarly rare 30-day operative mortality rates between the groups. ${ }^{1,43,44}$ In the Comparison of Surveillance vs Aortic Endografting for Small Aneurysm Repair (CAESAR) trial, the early intervention group had a higher percentage of patients with any adverse events ( $19 \%$ vs $5 \% ; P<.01)$, any major morbidity related to repair at 30 days ( $18 \%$ vs $6 \% ; P=.01)$, endoleaks at 1 year ( $12 \%$ vs $2 \%$; $P=.028$ ), and reintervention ( $6 \%$ vs $0 \% ; P=.03$ ) but similar rates of any major morbidity over the trial duration (3.3\% vs $2.8 \%$; $P=$.99). ${ }^{1,43}$ The Positive Impact of Endovascular Options for Treating Aneurysms Early (PIVOTAL) trial reported similar rates of adverse events at 30 days ( $12 \%$ vs $10 \%$ ) and at 1 year ( $26 \%$ vs $35 \%$ ), as well as reintervention ( $3.7 \%$ vs $4.6 \%$ ). ${ }^{1,44}$ Reported complication rates from registry data were generally comparable with rates reported in the above trials for 30-day operative mortality and reintervention. ${ }^{1}$

Two propranolol trials reported high discontinuation rates related to adverse events ( $38 \%$ and $60 \%$ of participants in the propranolol groups withdrew from the trials). Other medications (eg, angiotensin-converting enzyme inhibitors, calcium channel blockers, and antibiotics) seemed well tolerated based on rare trial withdrawals reported from 1 to 2 studies per drug class. ${ }^{1}$

\section{Response to Public Comment}

A draft version of this recommendation statement was posted for public comment on the USPSTF website from June 18 to July 15 , 2019. Some comments expressed concerns about the harms of screening. In response, the USPSTF added information about overtreatment as a harm of screening to the Supporting Evidence section and added information about comorbid conditions to the Practice Considerations section. Some comments urged more research in diverse populations. The USPSTF clarified its call for research in the Research Needs and Gaps section. Some comments suggested expanding the populations for whom screening is recommended. The USPSTF did not expand the scope of its recommendation beyond the populations justified by its review of the current evidence and recommends research about the benefits and harms of screening in these groups.

\section{Research Needs and Gaps}

Addressing several key research gaps could help inform the benefit of screening for AAA in US-based populations':

- Although evidence shows that women who smoke or have a family history are at increased risk for AAA compared with nonsmoking women without a family history, evidence is insufficient that screening this population confers a net benefit. Ideally, appropriately powered RCTs among women with risk factors could answer these critical gaps in the evidence on screening for AAA. In the absence of new trial data, high-quality, well-calibrated modeling studies based on reliable data on the harms and benefits of screening in women who smoke or in men and women with a family history of AAA may be informative.

-Well-conducted cohort studies examining rescreening benefits (including growth rates and health outcomes) are needed for persons who initially screen negative for AAA to determine the benefit and timing of additional screening ultrasonography.

- External validation of risk prediction models that have already been developed will allow policy makers to assess their value for making more individualized screening recommendations.

- Epidemiologic studies on the current prevalence of AAA in the United States, including in subpopulations, would help inform the applicability of older population-based screening trials to the current US population.

- Well-designed studies, RCTs, or registry data on the thresholds for repair of AAA in women may inform the benefits and harms of screening in women, as evidence suggests that AAAs in women may rupture at a smaller size than in men.

- Studies examining systems approaches to improving implementation of evidence-based AAA screening in the United States are needed.

- Studies examining the efficacy of screening and treatment in diverse populations (eg, older adults, women, and racial/ethnic groups) are needed to inform the need for specific recommendations in subpopulations of Americans.

\section{Recommendations of Others}

The American College of Cardiology and the American Heart Association jointly recommend 1-time screening for AAA with physical examination and ultrasonography in men aged 65 to 75 years who have ever smoked or in men 60 years or older who are the sibling or offspring of a person with AAA. These organizations do not recommend screening for AAA in men who have never smoked or in women. ${ }^{46}$ The Society for Vascular Surgery recommends 1-time ultrasonography screening for AAA in all men and women aged 65 to 75 years with a history of tobacco use, men 55 years or older with a family history of $A A A$, and women 65 years or older who have smoked or have a family history of AAA ${ }^{47}$ The American College of Preventive Medicine recommends 1-time screening in men aged 65 to 75 years who have ever smoked; it does not recommend routine screening in women. ${ }^{48}$ 


\section{ARTICLE INFORMATION}

Accepted for Publication: October 30, 2019

The US Preventive Services Task Force (USPSTF) members: Douglas K. Owens, MD, MS; Karina W. Davidson, PhD, MASc; Alex H. Krist, MD, MPH; Michael J. Barry, MD; Michael Cabana, MD, MA, $\mathrm{MPH}$; Aaron B. Caughey, MD, PhD; Chyke A. Doubeni, MD, MPH; John W. Epling Jr, MD, MSEd; Martha Kubik, PhD, RN; C. Seth Landefeld, MD; Carol M. Mangione, MD, MSPH; Lori Pbert, PhD; Michael Silverstein, MD, MPH; Melissa A. Simon, MD, MPH; Chien-Wen Tseng, MD, MPH, MSEE; John B. Wong, MD.

Affiliations of The US Preventive Services Task Force (USPSTF) members: Veterans Affairs Palo Alto Health Care System, Palo Alto, California (Owens); Stanford University, Stanford, California (Owens); Feinstein Institute for Medical Research, Northwell Health, Manhasset, New York (Davidson); Fairfax Family Practice Residency, Fairfax, Virginia (Krist); Virginia Commonwealth University, Richmond (Krist); Harvard Medical School, Boston, Massachusetts (Barry); University of California, San Francisco (Cabana); Oregon Health \& Science University, Portland (Caughey); Mayo Clinic, Rochester, Minnesota (Doubeni); Virginia Tech Carilion School of Medicine, Roanoke (Epling Jr); Temple University, Philadelphia, Pennsylvania (Kubik); University of Alabama at Birmingham (Landefeld); University of California, Los Angeles (Mangione); University of Massachusetts Medical School, Worcester (Pbert); Boston University, Boston, Massachusetts (Silverstein); Northwestern University, Evanston, Illinois (Simon); University of Hawaii, Honolulu (Tseng); Pacific Health Research and Education Institute, Honolulu, Hawaii (Tseng); Tufts University School of Medicine, Boston, Massachusetts (Wong)

Author Contributions: Dr Owens had full access to all of the data in the study and takes responsibility for the integrity of the data and the accuracy of the data analysis. The USPSTF members contributed equally to the recommendation statement.

Conflict of Interest Disclosures: Authors followed the policy regarding conflicts of interest described at https://www.uspreventiveservicestaskforce.org/ Page/Name/conflict-of-interest-disclosures. All members of the USPSTF receive travel reimbursement and an honorarium for participating in USPSTF meetings. Dr Barry reported receiving grants and personal fees from Healthwise, a nonprofit, outside the submitted work. No other disclosures were reported.

Funding/Support: The USPSTF is an independent, voluntary body. The US Congress mandates that the Agency for Healthcare Research and Quality (AHRQ) support the operations of the USPSTF.

Role of the Funder/Sponsor: AHRQ staff assisted in the following: development and review of the research plan, commission of the systematic evidence review from an Evidence-based Practice Center, coordination of expert review and public comment of the draft evidence report and draft recommendation statement, and the writing and preparation of the final recommendation statement and its submission for publication. AHRQ staff had no role in the approval of the final recommendation statement or the decision to submit for publication.
Disclaimer: Recommendations made by the USPSTF are independent of the US government. They should not be construed as an official position of AHRQ or the US Department of Health and Human Services.

Additional Contributions: We thank Iris Mabry-Hernandez, MD, MPH (AHRQ), who contributed to the writing of the manuscript, and Lisa Nicolella, MA (AHRQ), who assisted with coordination and editing.

Additional Information: The USPSTF makes recommendations about the effectiveness of specific preventive care services for patients without obvious related signs or symptoms. It bases its recommendations on the evidence of both the benefits and harms of the service and an assessment of the balance. The USPSTF does not consider the costs of providing a service in this assessment. The USPSTF recognizes that clinical decisions involve more considerations than evidence alone. Clinicians should understand the evidence but individualize decision-making to the specific patient or situation. Similarly, the USPSTF notes that policy and coverage decisions involve considerations in addition to the evidence of clinical benefits and harms.

\section{REFERENCES}

1. Guirguis-Blake JM, Beil TL, Senger CA, Coppola EL. Primary Care Screening for Abdominal Aortic Aneurysm: Updated Systematic Review for the US Preventive Services Task Force: Evidence Synthesis No. 184. Rockville, MD: Agency for Healthcare Research and Quality; 2019. AHRQ publication 19-05253-EF-1.

2. Guirguis-Blake JM, Beil TL, Senger CA, Coppola EL. Primary care screening for abdominal aortic aneurysm: evidence report and systematic review for the US Preventive Services Task Force [published December 10, 2019]. JAMA. doi:10.1001/ jama.2019.17021

3. Svensjö S, Björck M, Gürtelschmid M, Djavani Gidlund K, Hellberg A, Wanhainen A. Low prevalence of abdominal aortic aneurysm among 65-year-old Swedish men indicates a change in the epidemiology of the disease. Circulation. 2011;124 (10):1118-1123. doi:10.1161/CIRCULATIONAHA.111. 030379

4. Benson RA, Poole R, Murray S, Moxey P, Loftus IM. Screening results from a large United Kingdom abdominal aortic aneurysm screening center in the context of optimizing United Kingdom National Abdominal Aortic Aneurysm Screening Programme protocols. J Vasc Surg. 2016;63(2):301304. doi:10.1016/j.jvs.2015.08.091

5. Choke E, Vijaynagar B, Thompson J, Nasim A, Bown MJ, Sayers RD. Changing epidemiology of abdominal aortic aneurysms in England and Wales: older and more benign? Circulation. 2012;125(13): 1617-1625. doi:10.1161/CIRCULATIONAHA.111.077503

6. Anjum A, Powell JT. Is the incidence of abdominal aortic aneurysm declining in the 21st century? mortality and hospital admissions for England \& Wales and Scotland. Eur J Vasc Endovasc Surg. 2012;43(2):161-166. doi:10.1016/j.ejvs.2011.11. 014

7. Sandiford P, Mosquera D, Bramley D. Trends in incidence and mortality from abdominal aortic aneurysm in New Zealand. Br J Surg. 2011;98(5): 645-651. doi:10.1002/bjs.7461

8. Wanhainen A, Hultgren R, Linné A, et al; Swedish Aneurysm Screening Study Group (SASS). Outcome of the Swedish Nationwide Abdominal Aortic Aneurysm Screening Program. Circulation. 2016;134 (16):1141-1148. doi:10.1161/CIRCULATIONAHA.116. 022305

9. Johansson M, Zahl PH, Siersma V, Jørgensen KJ, Marklund B, Brodersen J. Benefits and harms of screening men for abdominal aortic aneurysm in Sweden: a registry-based cohort study. Lancet. 2018:391(10138):2441-2447. doi:10.1016/S0140-6736 (18)31031-6

10. Grøndal N, Søgaard R, Lindholt JS. Baseline prevalence of abdominal aortic aneurysm, peripheral arterial disease and hypertension in men aged 65-74 years from a population screening study (VIVA trial). Br J Surg. 2015;102(8):902-906. doi: $10.1002 /$ bjs.9825

11. Reimerink JJ, van der Laan MJ, Koelemay MJ, Balm R, Legemate DA. Systematic review and meta-analysis of population-based mortality from ruptured abdominal aortic aneurysm. Br J Surg. 2013;100(11):1405-1413. doi:10.1002/bjs.9235

12. US Preventive Services Task Force. Procedure Manual. https://www.uspreventiveservicestaskforce. org/Page/Name/procedure-manual. Published June 2018. Accessed October 15, 2019.

13. Lindholt JS, Juul S, Fasting $\mathrm{H}$, Henneberg EW. Screening for abdominal aortic aneurysms: single centre randomised controlled trial. BMJ. 2005;330 (7494):750. doi:10.1136/bmj.38369.620162.82

14. Kent KC, Zwolak RM, Egorova NN, et al Analysis of risk factors for abdominal aortic aneurysm in a cohort of more than 3 million individuals. J Vasc Surg. 2010;52(3):539-548. doi: 10.1016/j.jvs.2010.05.090

15. Wilmink AB, Hubbard CS, Day NE, Quick CR. The incidence of small abdominal aortic aneurysms and the change in normal infrarenal aortic diameter implications for screening. Eur J Vasc Endovasc Surg. 2001;21(2):165-170. doi:10.1053/ejvs.2000.1285

16. Vardulaki KA, Walker NM, Day NE, Duffy SW, Ashton HA, Scott RA. Quantifying the risks of hypertension, age, sex and smoking in patients with abdominal aortic aneurysm. Br J Surg. 2000;87(2): 195-200. doi:10.1046/j.1365-2168.2000.01353.x

17. van Vlijmen-van Keulen CJ, Pals G, Rauwerda JA. Familial abdominal aortic aneurysm: a systematic review of a genetic background. Eur J Vasc Endovasc Surg. 2002;24(2):105-116. doi:10. 1053/ejvs.2002.1692

18. MacSweeney ST, O'Meara M, Alexander C, O'Malley MK, Powell JT, Greenhalgh RM. High prevalence of unsuspected abdominal aortic aneurysm in patients with confirmed symptomatic peripheral or cerebral arterial disease. Br J Surg. 1993;80(5):582-584. doi:10.1002/bjs.1800800510

19. Lederle FA, Johnson GR, Wilson SE, et al; The Aneurysm Detection and Management (ADAM) Veterans Affairs Cooperative Study Investigators. Relationship of age, gender, race, and body size to infrarenal aortic diameter. J Vasc Surg. 1997;26 (4):595-601. doi:10.1016/S0741-5214(97)70057-0

20. Li X, Zhao G, Zhang J, Duan Z, Xin S. Prevalence and trends of the abdominal aortic aneurysms 
epidemic in general population-a meta-analysis. PLoS One. 2013;8(12):e81260. doi:10.1371/journal. pone.0081260

21. De Rango $P$, Farchioni L, Fiorucci $B$, Lenti M. Diabetes and abdominal aortic aneurysms. Eur J Vasc Endovasc Surg. 2014;47(3):243-261. doi:10. 1016/j.ejvs.2013.12.007

22. Lederle FA, Johnson GR, Wilson SE, et al: Aneurysm Detection and Management Veterans Affairs Cooperative Study Investigators. The aneurysm detection and management study screening program: validation cohort and final results. Arch Intern Med. 2000;160(10):1425-1430. doi:10.1001/archinte.160.10.1425

23. Takagi $\mathrm{H}$, Umemoto T; ALICE (All-Literature Investigation of Cardiovascular Evidence) Group. Negative association of diabetes with rupture of abdominal aortic aneurysm. Diab Vasc Dis Res. 2016;13(5):341-347. doi:10.1177/1479164116651389

24. Xiong J, Wu Z, Chen C, Wei Y, Guo W. Association between diabetes and prevalence and growth rate of abdominal aortic aneurysms: a meta-analysis. Int J Cardiol. 2016;221:484-495. doi:10.1016/j.ijcard.2016.07.016

25. Joergensen TM, Houlind K, Green A, Lindholt JS. Abdominal aortic diameter is increased in males with a family history of abdominal aortic aneurysms: results from the Danish VIVA-trial. Eur J Vasc Endovasc Surg. 2014;48(6):669-675. doi:10. 1016/j.ejvs.2014.09.005

26. Chaikof EL, Dalman RL, Eskandari MK, et al The Society for Vascular Surgery practice guidelines on the care of patients with an abdominal aortic aneurysm. J Vasc Surg. 2018;67(1):2-77. doi:10. 1016/j.jvs.2017.10.044

27. Lederle FA, Walker JM, Reinke DB. Selective screening for abdominal aortic aneurysms with physical examination and ultrasound. Arch Intern Med. 1988;148(8):1753-1756. doi:10.1001/archinte. 1988.00380080049015

28. Lindholt JS, Vammen S, Juul S, Henneberg EW, Fasting $\mathrm{H}$. The validity of ultrasonographic scanning as screening method for abdominal aortic aneurysm. Eur J Vasc Endovasc Surg. 1999;17(6): 472-475. doi:10.1053/ejvs.1999.0835

29. Costantino TG, Bruno EC, Handly N, Dean AJ. Accuracy of emergency medicine ultrasound in the evaluation of abdominal aortic aneurysm. J Emerg Med. 2005;29(4):455-460. doi:10.1016/j. jemermed.2005.02.016

30. Tayal VS, Graf CD, Gibbs MA. Prospective study of accuracy and outcome of emergency ultrasound for abdominal aortic aneurysm over two years. Acad Emerg Med. 2003;10(8):867-871. doi:10.1197/ aemj.10.8.867

31. Rubano E, Mehta N, Caputo W, Paladino L, Sinert R. Systematic review: emergency department bedside ultrasonography for diagnosing suspected abdominal aortic aneurysm. Acad Emerg Med. 2013;20(2):128-138. doi:10.1111/ acem.12080

32. Lederle FA, Simel DL. The rational clinica examination: does this patient have abdominal aortic aneurysm? JAMA. 1999;281(1):77-82. doi:10 1001/jama.281.1.77

33. Scott RA, Bridgewater SG, Ashton HA Randomized clinical trial of screening for abdominal aortic aneurysm in women. Br J Surg. 2002;89(3) 283-285. doi:10.1046/j.0007-1323.2001.02014.x

34. Ulug $P$, Sweeting MJ, von Allmen RS, Thompson SG, Powell JT; SWAN Collaborators. Morphological suitability for endovascular repair, non-intervention rates, and operative mortality in women and men assessed for intact abdominal aortic aneurysm repair: systematic reviews with meta-analysis. Lancet. 2017;389(10088):2482-2491. doi:10.1016/S0140-6736(17)30639-6

35. LeFevre ML; US Preventive Services Task Force. Screening for abdominal aortic aneurysm: U.S. Preventive Services Task Force recommendation statement. Ann Intern Med. 2014;161(4):281-290. doi:10.7326/M14-1204

36. Ashton HA, Buxton MJ, Day NE, et al; Multicentre Aneurysm Screening Study Group. The Multicentre Aneurysm Screening Study (MASS) into the effect of abdominal aortic aneurysm screening on mortality in men: a randomised controlled trial. Lancet. 2002;360(9345):1531-1539. doi:10.1016/ s0140-6736(02)11522-4

37. Norman PE, Jamrozik K, Lawrence-Brown MM, et al. Population based randomised controlled trial on impact of screening on mortality from abdominal aortic aneurysm. BMJ. 2004;329(7477): 1259. doi:10.1136/bmj.329.7477.1259

38. Scott RA, Wilson NM, Ashton HA, Kay DN Influence of screening on the incidence of ruptured abdominal aortic aneurysm: 5-year results of a randomized controlled study. Br J Surg. 1995;82(8): 1066-1070. doi:10.1002/bjs.1800820821

39. McCaul KA, Lawrence-Brown M, Dickinson JA Norman PE. Long-term outcomes of the Western Australian trial of screening for abdominal aortic aneurysms: secondary analysis of a randomized clinical trial. JAMA Intern Med. 2016;176(12):1761-1767. doi:10.1001/jamainternmed.2016.6633

\section{Svensjö S, Björck M, Wanhainen A}

Current prevalence of abdominal aortic aneurysm in 70-year-old women. Br J Surg. 2013;100(3):367372. doi:10.1002/bjs.8984

41. Lederle FA, Wilson $S E$, Johnson GR, et al; Aneurysm Detection and Management Veterans Affairs Cooperative Study Group. Immediate repair compared with surveillance of small abdominal aortic aneurysms. N Engl J Med. 2002;346(19): 1437-1444. doi:10.1056/NEJMoa012573

42. Powell JT, Brady AR, Brown LC, et al; The UK Small Aneurysm Trial Participants. Mortality results for randomised controlled trial of early elective surgery or ultrasonographic surveillance for small abdominal aortic aneurysms. Lancet. 1998 352(9141):1649-1655. doi:10.1016/S0140-6736(98) 10137-X

43. Cao P, De Rango P, Verzini F, Parlani G, Romano L, Cieri E; CAESAR Trial Group. Comparison of surveillance versus aortic endografting for small aneurysm repair (CAESAR): results from a randomised trial. Eur J Vasc Endovasc Surg. 2011;41 (1):13-25. doi:10.1016/j.ejvs.2010.08.026

44. Ouriel K, Clair DG, Kent KC, Zarins CK; Positive Impact of Endovascular Options for Treating Aneurysms Early (PIVOTAL) Investigators. Endovascular repair compared with surveillance for patients with small abdominal aortic aneurysms. J Vasc Surg. 2010;51(5):1081-1087. doi:10.1016/j.jvs. 2009.10.113

45. Lindholt JS, Søgaard R. Population screening and intervention for vascular disease in Danish men (VIVA): a randomised controlled trial. Lancet. 2017; 390(10109):2256-2265. doi:10.1016/S0140-6736(17) 32250-X

46. Hirsch AT, Haskal ZJ, Hertzer NR, et al; American Association for Vascular Surgery; Society for Vascular Surgery; Society for Cardiovascular Angiography and Interventions; Society for Vascular Medicine and Biology; Society of Interventional Radiology: ACC/AHA Task Force on Practice Guidelines Writing Committee to Develop Guidelines for the Management of Patients With Peripheral Arterial Disease; American Association of Cardiovascular and Pulmonary Rehabilitation; National Heart, Lung, and Blood Institute; Society for Vascular Nursing; TransAtlantic Inter-Society Consensus; Vascular Disease Foundation. ACC/AHA 2005 Practice Guidelines for the management of patients with peripheral arterial disease (lower extremity, renal, mesenteric, and abdominal aortic) a collaborative report from the American Association for Vascular Surgery/Society for Vascular Surgery, Society for Cardiovascular Angiography and Interventions, Society for Vascular Medicine and Biology, Society of Interventional Radiology, and the ACC/AHA Task Force on Practice Guidelines (Writing Committee to Develop Guidelines for the Management of Patients With Peripheral Arterial Disease): endorsed by the American Association of Cardiovascular and Pulmonary Rehabilitation; National Heart, Lung, and Blood Institute; Society for Vascular Nursing; TransAtlantic Inter-Society Consensus; and Vascular Disease Foundation. Circulation. 2006;113(11): e463-e654.

47. Chaikof EL, Brewster DC, Dalman RL, et al; Society for Vascular Surgery. The care of patients with an abdominal aortic aneurysm: the Society for Vascular Surgery practice guidelines. J Vasc Surg. 2009;50(4)(suppl):S2-S49. doi:10.1016/j.jvs.2009. 07.002

48. Lim LS, Haq N, Mahmood S, Hoeksema L; ACPM Prevention Practice Committee; American College of Preventive Medicine. Atherosclerotic cardiovascular disease screening in adults: American College of Preventive Medicine position statement on preventive practice. Am J Prev Med. 2011;40(3):381.e1-381.e10. doi:10.1016/j.amepre. 2010.11.021 